\title{
Genetic Diversity of Colombian Sylvatic Trypanosoma cruzi Isolates Revealed by the Ribosomal DNA
}

\author{
Patricia Cuervo*, Elisa Cupolillo**, Iris Segura*, Nancy Saravia*, 0 ctavio Fernandes/***/+
}

\author{
Departamento de MedicinaTropical **Departamento de Imunologia, Instituto Oswaldo Cruz-Fiocruz, Av. Brasil 4365, $21045-$ \\ 900 Rio de Janeiro, RJ, Brasil *Centro Internacional de Entrenamiento e Investigaciones Médicas, Cali, Colombia \\ ***Universidade do Estado de Rio de Janeiro, Rio de Janeiro, RJ, Brasil
}

\begin{abstract}
American trypanosomiasis is a common zoonosis in Colombia and Trypanosoma cruzi presents a wide distribution throughout the country. Although some studies based on enzyme electrophoresis profiles have described the population structure of the parasite, very few molecular analyses of genotipic markers have been conducted using Colombian strains. In this study, we amplified the non-transcribed spacer of the mini-gene by PCR, typing the isolates as T. cruzi I, T. cruzi zymodeme 3 or T. rangeli. In addition, the internal transcribed spacers of the ribosomal gene concomitant with the 5.8S rDNA were amplified and submitted to restriction fragment polymorphism analysis. The profiles were analyzed by a numerical methodology generating a phenetic dendrogram that shows heterogeneity among the $\mathrm{T}$. cruzi isolates. This finding suggests a relationship between the complexity of the sylvatic transmission cycle in Colombia and the diversity of the sylvan parasites.
\end{abstract}

Key words: Trypanosoma cruzi - internal transcribed spacers - mini-exon gene - ribosomal DNA - Colombia

Trypanosoma cruzi is a zoonotic protozoan parasite that is perpetuated in nature through a transmission cycle that involves triatomines, the invertebrate vectors, and wild mammal reservoirs. Eventually, with the adaptation of the insects to human dwellings, a domiciliary cycle is established and domestic animals may became reservoirs of T. cruzi. The proximity of the domiciliary transmission cycle to humans results in the latter becoming an accidental host, and victim of Chagas disease.

Biochemical and molecular markers have been investigated in order to find correlations between T. cruzi phenotypes or genotypes and the different biological and epidemiological features of these adaptable organisms. Studies based on enzyme electrophoretic profiles (Miles et al. 1977, 1978, 1980) identified three distinct zymodemes of T. cruzi isolates in Brazil: zymodeme 1 (Z1) and 3 (Z3), associated with the sylvatic environment, and zymodeme 2 (Z2) with the domestic transmission cycle.

A high degree of variability was corroborated and extended when more loci where analyzed and after the application of a plethora of distinct molecular methods (Morel et al. 1986, Tibayrenc \& Ayala 1988, Macedo et al. 1992, Henriksson et al. 1996). Nevertheless, this diversity could not be consistently correlated with a particular clinical presentation, epidemiological circumstances of transmission or geographical origin.

${ }^{+}$Corresponding author. Fax: +55-21-2280.3740. E-mail: octaviof@gene.dbbm.fiocruz.br

Received 31 August 2001

Accepted 27 June 2002
Despite the aforementioned diversity, PCR amplification of sequences from the $24 \mathrm{~S} \alpha$ ribosomal RNA gene and from the mini-exon gene non-transcribed spacer, demonstrated a dimorphism among T. cruzi isolates (Souto et al. 1996, Fernandes et al. 1998a, 1999) that correlates with Z1 (T. cruzi I) and Z2 (T. cruzi II) (Fernandes et al. 1998a, $1999)$. Further analysis of the mini-exon gene of $Z 3$ isolates defined this group as a discrete cluster but related to T. cruzi I (Fernandes et al. 1998b).

In Colombia, Saravia et al. (1987) observed that isolates from different hosts, ecological settings and geographic locations belong to Z1 and/or Z3. Zymodeme 1 stocks were found to circulate both in the sylvatic and domestic environment and Z3 was found exclusively in the sylvatic cycle. Further biochemical and molecular analysis of Colombian T. cruzi strains from several distinct geographic origins confirmed the previous findings and the geographic confinement of certain stocks was described (Jaramillo et al. 1999).

In the current report, using a multiplex PCR assay based on the non-transcribed spacer of the mini-exon gene (Fernandes et al. 2001), 14 Colombian Trypanosoma isolates from distinct hosts and geographic regions were typed, observing that they could be clustered into T. cruzi I (ten stocks), T. cruzi Z3 (two stocks) and T. rangeli (two stocks). T. dionisi was used as a negative control confirming the specificity of the proposed primers (Fernandes et al. 2001), showing no amplified products (Table, Figure).

Intra cluster heterogeneity was investigated using a typing approach based on the variability of the internal transcribed spacer (ITS) of the ribosomal cistron (rDNA). Oligonulceotides were used to amplify the region corresponding to the 5.8S rDNA plus the two flanking ITS as described elsewhere (Cupolillo et al. 1995, Fernandes et 
al. 1999). The PCR products were further submitted to RFLP analysis with six endonucleases ( $R s a$ I, Hae III, Eco RI, Taq I, Bst UI and Sau 3AI). DNA fragments were sized after acrylamide gel electrophoresis and silver staining. The restriction profiles were analyzed by a numerical methodology (Jaccard's coefficient) and the generated matrix was analyzed by unweighted pair-group method with arithmetic averages (UPGMA) generating a phenetic dendrogram (Figure).

The analysis shows that all isolates typed by miniexon gene as T. cruzi I constituted a single cluster having two clearly demarcated groupings with a low level of similarity between them (0.233-0.676). The two Z3 isolates clustered together as a separate branch. T. rangeli strains defined another cluster, and $T$. dionisi was found to be the most divergent species among the group of strains analyzed. The two typing markers produced congruent results. The three principal clusters observed in the phenogram were corroborated by the multiplex PCR experiments, giving products of 200bp, 150bp and 100bp to T. cruzi I (TcI), T. cruzi Z3 (Z3) and T. rangeli (Tr), respectively (Figure). However, while intra-group polymorphism was revealed by the RFLP of the ITSrDNA no variation was observed in the size of the amplified spot of the nontranscribed spacer of the mini-exon gene, among isolates from the same group.

The two Z3 isolates present a low level of similarity between them. Both Z3 stocks were derived from the same tropical rain forest region (Tumaco, Southwest Colombia) but from different mammal hosts (Rattus sp. and Dassypus sp.). The genetic diversity found in Colombian Z3 isolates may be the reflection of its participation in the sylvatic cycle with the extreme biodiversity of putative mammals and vectors and therefore an increased possibility of independent cycles of transmission and selective pres- sures by different hosts. Cycles of genetically distinct parasites may be maintained in nature within specific hosts present in the same ecotope (Fernandes et al. 1999). As observed for isolates from the Brazilian Amazon basin, Z3 strains from Colombia seem to be associated with terrestrial habitats and ground dwelling mammals.

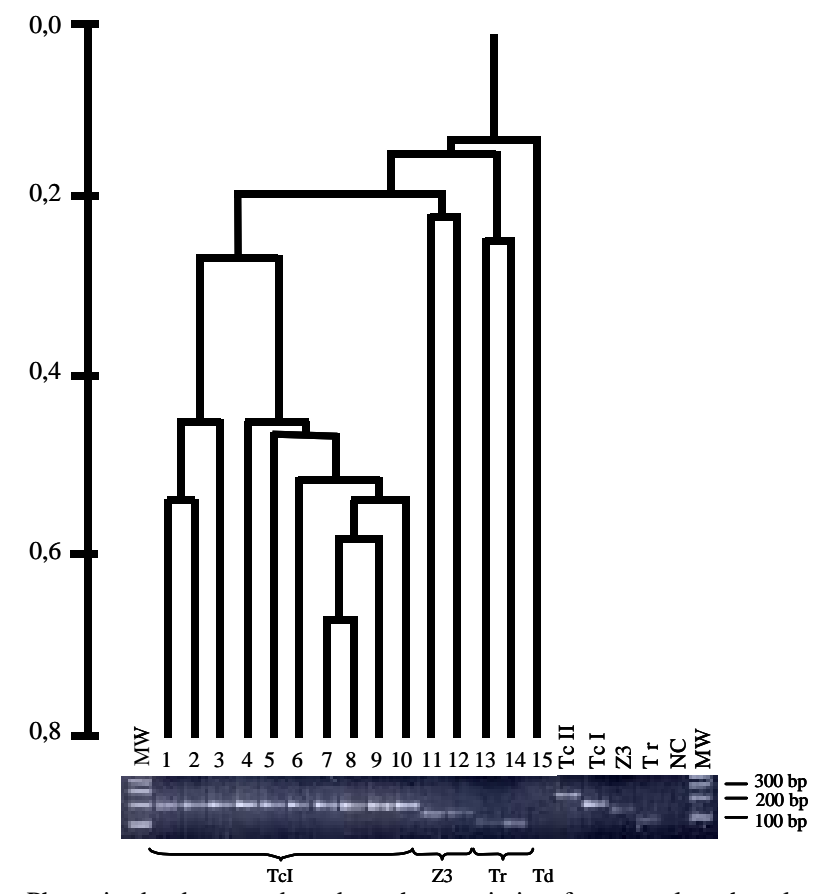

Phenetic dendrogram based on the restriction fragment length polymorphism of rDNA products (ITS $+5.8 \mathrm{~S}+\mathrm{ITS}$ ) and correlation with mini-exon genotypes of Trypanosoma sp. strains. Tc I: T. cruzi I; Tc II: T. cruzi II; Z3: zymodeme 3; Tr: T. rangeli; Td: T. dionisi; NC: negative control (no DNA was added to the reaction); MW: Molecular Weight Marker, 100 bp DNA ladder.

TABLE

Mini-exon gene genotypes of Colombian Trypanosoma sp. strains

\begin{tabular}{|c|c|c|c|c|c|c|}
\hline Code & Strain & $\begin{array}{l}\text { Geografic origin } \\
\text { (Municipality, Department) }\end{array}$ & Host & $\begin{array}{c}\text { Transmission } \\
\text { cycle }\end{array}$ & Zymodeme $^{c}$ & $\begin{array}{l}\text { Mini-exon } \\
\text { genotype }\end{array}$ \\
\hline 1 & $350^{a}$ & Tumaco, Nariño (SW) & Didelphis marsupialis & Sylvatic & Z1 like & TC I \\
\hline 2 & Xeno-37 & Villavicencio, Meta (CE) & Human & Domicilary & Z1 like & TC I \\
\hline 3 & Ep-74 $b$ & Orucue, Casanare (CE) & Rhodnius prolixus & Sylvatic & Z1 like & TC I \\
\hline 4 & $514^{a}$ & Tumaco, Nariño (SW) & D. marsupialis & Sylvatic & Z1 like & TC I \\
\hline 5 & Ep-243 ${ }^{b}$ & Puerto Gaitán, Meta (CE) & R. prolixus & Sylvatic & Z1 like & TC I \\
\hline 6 & $\mathrm{Ev}-70^{b}$ & Villavicencio, Meta (CE) & R.prolixus & Sylvatic & Z1 like & TC I \\
\hline 7 & $322^{a}$ & Tumaco, Nariño (SW) & Rattus rattus & Sylvatic & Z1 like & TC I \\
\hline 8 & Bp-18 & Guateque, Boyacá (CE) & Triatoma sp. & Domicilary & Z1 like & TC I \\
\hline 9 & $510^{a}$ & Tumaco, Nariño (SW) & D. marsupialis & Sylvatic & Z1 like & TC I \\
\hline 10 & Choachí 6 & Choachi, Cundinamarca (C) & $R$. prolixus & Domicilary & Z1 like & TC I \\
\hline 11 & $280^{a}$ & Tumaco, Nariño (SW) & Proechimys semiespinosus & Sylvatic & ND & $\mathrm{Z} 3$ \\
\hline 12 & $509^{a}$ & Tumaco, Nariño (SW) & Dassypus sp. & Sylvatic & ND & $\mathrm{Z3}$ \\
\hline 13 & $\mathrm{Ev}-39^{b}$ & Villavicencio, Meta (CE) & $R$. prolixus & Sylvatic & T. rangeli 2 & T. rangeli \\
\hline 14 & $508^{a}$ & Tumaco, Nariño (SW) & D. marsupialis & Sylvatic & T. rangeli 2 & T. rangeli \\
\hline 15 & T. dionisi & London/71/BPUC/3 & Bat & & & \\
\hline
\end{tabular}

$a$ : Travi et al. 1994; $b$ : Saravia et al. 1987; $c$ : zymodeme classification was previously described by Saravia et al. (1987). The isolate Choachí 6 was kindly provided by Dr Felipe Guhl, Universidad de los Andes, Bogotá, Colombia; ND: not determined. TC I: T. cruzi I; Z-3: zymodeme 3; SW: Southwest; SE: Southeast; CE: Eastern central; C: Central region. Code corresponds to the number depicted in the figure. 
Likewise, the two $T$. rangeli stocks were positioned in the same branch but had a low level of similarity. This may be attributable to the different host (Didelphis marsupialis and Rhodnius prolixus) or geographic origin (Southwest and Central-East Colombia) of the parasites. However very limited heterogeneity was detected among 16 strains of $T$. rangeli from different geographic regions and epidemiological circumstances in Colombia based on 13 different isoenzymes (Holguin et al 1987). Hence it is possible that this particular marker is more polymorphic than constitutive enzymes. It is interesting that two groups of $T$. rangeli were previously described by Vallejo et al. (1994) when amplifying the conserved region of minicircle molecules. Polymorphism among strains from distinct geografical origin was also evidenced using the mini-exon primary DNA sequence and low stringency single specific primer PCR (LSSP-PCR) profiles (Grisard et al. 1999). Therefore, as different markers are examined the finding of polymorphism among T. rangeli isolates is becoming a common observation.

The heterogeneity among $T$. cruzi I from Colombia, as shown in the phenogram, may be attributed to the different host origin of the isolates and suggests a complexity of the sylvatic transmission cycle in this area (D'Alessandro et al. 1984, Loyola et al. 1987, Travi et al. 1994). Both invertebrate (triatomines) and wild mammalian hosts may be acting as biological filters selecting parasite sub-populations, resulting in the presence of $T$. cruzi I as a predominant group in Colombia. In this country, the description of $\mathrm{Z} 1$ circulating in both the domestic and sylvan environment may seem to contrast with the findings in Brazil, where this zymodeme is preferentially associated with the sylvatic cycle.

Lainson et al. (1979) stated that cases of Chagas disease in the Brazilian Amazon might be derived from sporadic visit of wild triatomines to human dwellings near the forests or from the eventual contact of the inhabitants of a specific area with the sylvatic cycle of the parasite. Therefore, it is difficult to define the limit between the domestic and sylvatic environment in this setting. Probably, this is the same ecological scenario that occurs in Colombia, explaining the finding of $\mathrm{Z} 1$ in both the domestic and sylvatic transmission cycles of the parasite. T. cruzi I has been associated with low morbidity areas in Brazil (Fernandes et al. 1998a) and this may be the reason for the high rate of assymptomatic Chagas patients in Colombia. Consistent with the findings presented herein, the phylogenetic tree generated by UPGMA algorithm with Nei's genetic distance based on MLEE (13 loci) of 23 Colombian T. cruzi isolates (Ruiz-Garcia et al. 2000) shows two sub-populations of T. cruzi. However, no definition concerning $T$. cruzi groups (T. cruzi I, T. cruzi II or T. cruzi Z3) is assigned to any of the two major branches.

Our study shows two groups of T. cruzi: T. cruzi I and $\mathrm{Z3}$, associated with transmission cycles in Colombia, independently of the geographic origin of the isolates. Further work, particularly the analysis of sets of strains from sites where sylvatic and domiciliary transmission occur together and evaluation of pathogenicity in model systems as well as the inclusion of new markers will be necessary to assess the implications of the presence of these specific sub-populations in the epidemiology of American trypanosomiasis in Colombia.

\section{REFERENCES}

Cupolillo E, Grimaldi G, Momen H, Beverley S 1995. Intergenic region typing (IRT): a rapid molecular approach to the characterization and evolution of Leishmania. Mol Biochem Parasitol 73: 145-155.

D’Alessandro A, Barreto P, Saravia N, Barreto M 1984. Epidemiology of Trypanosoma cruzi in the oriental plains of Colombia. Am J Trop Med Hyg 33: 1084-1095.

Fernandes O, Mangia R, Lisboa C, Pinho A, Morel C, Zingales B, Campbell D, Jansen A 1999. The complexity of the sylvatic cycle of Trypanosoma cruzi in Rio de Janeiro state (Brazil) revealed by the non-transcribed spacer of the miniexon gene. Parasitology 118: 161-166.

Fernandes O, Santos S, Cupolillo E, Mendonça B, Derré R, Junqueira A, Santos L, Sturm N, Naiff R, Barret T, Campbell D, Coura JR 2001 Trypanosomiasis in the Brazilian Amazon: a mini-exon multiplex PCR to distinguish the major groups of Trypanosoma cruzi and T. rangeli. Trans $R$ Soc Trop Med Hyg 95: 97-99.

Fernandes O, Souto R, Castro J, Borges J, Carrara N, Junqueira A, Naiff R, Barrett T, Degrave W, Zingales B, Campbell D, Coura JR 1998a. Brazilian isolates of Trypanosoma cruzi from humans and triatomines classified into two lineages using mini-exon and ribosomal RNA sequences. Am J Trop Med Hyg 58: 807-811.

Fernandes O, Sturm N, Derré R, Campbell D 1998b. The miniexon gene: a genetic marker for zymodeme III of Trypanosoma cruzi. Mol Biochem Parasitol 95: 129-133.

Grisard E, Campbell D, Romanha A 1999. Mini-exon gene sequence polymorphism among Trypanosoma rangeli strains isolated from distinct geografical regions. Parasitology 118 : 375-382.

Henriksson J, Aslund L, Pettersson U 1996. Karyotype variability in Trypanosoma cruzi. Parasitol Today 12: 108-114.

Holguin A, Saravia N, D'Alessandro A 1987. Lack of enzyme polymorphism in Trypanosoma rangeli stocks from sylvatic and domiciliary transmission cycles in Colombia. Am J Trop Med Hyg 36: 53-58.

Jaramillo N, Moreno J, Triana O, Arcos-Burgos M, Muñoz S, Solari A 1999. Genetic structure and phylogenetic relationships of Colombian Trypanosoma cruzi populations as determined by schizodeme and isoenzyme markers. Am J Trop Med Hyg 6: 986-993.

Lainson J, Shaw J, Frainha H, Miles M, Draper C 1979. Chaga's disease in the Amazon Basin. I. Trypanosoma cruzi infections in sylvatic mammals, triatomine bugs and man in the state of Pará, north Brazil. Trans R Soc Trop Med Hyg 73: 193-204.

Loyola E, Freyre J, Holguin A, Sanchez A, Gonzalez A, Barreto M 1987. Trypanosoma cruzi infections in sylvatic hosts on the Pacific coast of Colombia. Trans R Soc Trop Med Hyg 81: 760 .

Macedo A, Martins M, Chiari E, Pena S 1992. DNA fingerprinting of Trypanosoma cruzi: a new tool for characterization of strains and clones. Mol Biochem Parasitol 55: 147154.

Miles M, Lanham S, Souza A, Povoa M 1980. Further enzymic character of Trypanosoma cruzi and their evaluation for strain identification. Trans R Soc Trop Med Hyg 74: 221237.

Miles M, Souza A, Povoa M Shaw J, Lainson R, Toye P 1978. Isozymic heterogeneity of Trypanosoma cruzi in the first authoctonus patients with Chagas' disease in Amazonian Brazil. Nature 272: 819-821. 
Miles M, Toye P, Oswald S, Godfrey D 1977. The identification by isoenzyme patterns of two distinct stain-groups of Trypanosoma cruzi, circulating independently in a rural area of Brazil. Trans R Soc Trop Med Hyg 71: 217-225.

Morel C, Deane M, Gonçalves A 1986. The complexity of Trypanosoma cruzi populations revelead by schizodeme analysis. Parasitol Today 4: 97-101.

Ruiz-Garcia M, Montilla M, Nicholls SO, Angarita L, Alvarez D 2000. Genetic relationships and spatial genetic structure among clonal stocks of Trypanosoma cruzi in Colombia. Heredity $85 \mathrm{Pt}$ 4: 318-327.

Saravia N, Holguín A, Cibulskis R, D’Alessandro A 1987. Divergent isoenzyme profiles of sylvatic and domicialiary Trypanosoma cruzi in the eastern plains, piedmont, and highlands of Colombia. Am J Trop Med Hyg 36: 59-69.

Souto R, Fernandes O, Macedo A, Campbell D, Zingales B
1996. DNA markers define two major phylogenetic lineages of Trypanosoma cruzi. Mol Biochem Parasitol 83: 141-152.

Tibayrenc M, Ayala F 1988. Isoenzyme variability in Trypanosoma cruzi, the agent of Chagas' disease: genetical, taxonomical, and epidemiological significance. Evolution 42: 277-292.

Travi B, Jaramillo C, Montoya J, Segura I, Zea A, Gonçalves A, Velez I 1994. Didelphis marsupialis, an important reservoir of Trypanosoma (Schizotrypanum) cruzi and Leishmania (Leishmania) chagasi in Colombia. Am J Trop Med Hyg 50: 557-565.

Vallejo G, Macedo A, Chiari E, Pena S 1994. The kinetoplast DNA from Trypanosoma rangeli contains two distinct classes of minicircle with different size and molecular organization. Mol Biochem Parasitol 67: 245-253. 